REVIEW

\title{
ANTENATAL CARE AS A MEANS OF INCREASING BIRTH IN THE HEALTH FACILITY AND REDUCING MATERNAL MORTALITY: A SYSTEMATIC REVIEW
}

\author{
Yifru Berhan ${ }^{1}$, Asres Berhan ${ }^{2}$
}

\begin{abstract}
BACKGROUND: Although there is a general agreement on the importance of antenatal care to improve the maternal and perinatal health, little is known about its importance to improve health facility delivery in developing countries. The objective of this study was to assess the association of antenatal care with birth in health facility.

METHODS: A systematic review with meta-analysis of Mantel-Haenszel odds ratios was conducted by including seventeen small scale studies that compared antenatal care and health facility delivery between 2003 and 2013. Additionally, national survey data of African countries which included antenatal care, health facility delivery and maternal mortality in their report were included. Data were accessed via a computer based search from MEDLINE, African Journals Online, HINARI and Google Scholar databases.

RESULTS: The regression analysis of antenatal care with health facility delivery revealed a positive correlation. The pooled analysis also demonstrated that woman attending antenatal care had more than 7 times increased chance of delivering in a health facility. The comparative descriptive analysis, however, demonstrated a big gap between the proportion of antenatal care and health facility delivery by the same individuals (27\%-95\% vs 4\%-45\%). Antenatal care and health facility delivery had negative correlation with maternal mortality.

CONCLUSION: The present regression and meta-analysis has identified the relative advantage of having antenatal care to give birth in health facilities. However, the majority of women who had antenatal care did not show up to a health facility for delivery. Therefore, future research needs to give emphasis to identifying barriers to health facility delivery despite having antenatal care follow up.

KEYWORDS: antenatal care, community based studies, developing countries, health facility delivery, meta-analysis
\end{abstract}

DOI: http://dx.doi.org/10.4314/ejhs.v24i1.9S

\section{INTRODUCTION}

In contemporary obstetrics, antenatal care is a medical service provided to a woman throughout her pregnancy in order to ensure that pregnancy and childbirth will not have a detrimental effect to herself and her baby. To emphasize its importance, antenatal care was one of the four pillars of the Safe Motherhood Initiative (1). Accessible literature has shown that antenatal care dates back to the $18^{\text {th }}$ century (2) and developed in the $19^{\text {th }}$ century although some questioned its relevance in the 1990s (3-5). Nevertheless, there is a general agreement on the importance of antenatal care to improve the maternal and perinatal health (6). It was also pointed out that the

\footnotetext{
${ }^{1}$ Hawassa University, College of Medicine and Health Sciences, Department of Gynecology-Obstetrics

${ }^{2}$ Hawassa University, College of Medicine and Health Sciences, Department of Pharmacology

Corresponding Author: Yifru Berhan, Email: yifrub@yahoo.com
} 
utilization of antenatal care services may lead to institutional delivery, seeking advice for pregnancy complications, and seeking advice for post-delivery complications (7), but there are several inconsistent reports (8-26).

The conventional approach/European model of antenatal care was developed in the early 1900 's, assuming that multiple visits were better in the care of pregnant women and their babies than few visits. As a result, frequent visits were the norm, and women were classified as high and low risk to have antepartum, intrapartum or postpartum complications (27). A global evaluation of antenatal care, however, came up with a new model, which was endorsed by the World Health Organization (WHO), to deliver antenatal services in 4 focused visits (focused antenatal care). The schedule is first early in the first trimester, $2^{\text {nd }}$ between 4-6 months, $3^{\text {rd }}$ between 7-8 months and $4^{\text {th }}$ at term unless indicated (28).

Although there are controversies across the world with regard to making the antenatal care visits conventional or focused type, several developing countries adopted the new antenatal care model as a standard $(28,29)$. Taking this into account, the demographic and health surveys across developing countries gave emphasis in their report to 4 antenatal care visits as one of the indicators for quality of antenatal care (8). In this review of the national data, at least 4 antenatal care visits were entertained.

Beyond the number of visits, however, antenatal care is said to be fully effective if it makes the mother prepared to deliver under the care of a skilled health attendant (30). In other words, some argue that unless the antenatal care service becomes a bridge to birth in the health facility, it may not help much to identify and treat the major obstetric complications that commonly occur during and after delivery (obstructed labor, uterine rupture, postpartum hemorrhage and sepsis) (31).

With this regard, there are several studies that showed high antenatal care coverage compounded with low skilled attendance during delivery (32, 33). However, there is no systematic review that has shown the gap or the pooled effect of antenatal care on health facility delivery and the gross estimation of maternal mortality in relation to antenatal care. Therefore, this systematic review was planned to show the gap between the proportion of antenatal care and health facility delivery, the association of antenatal care with birth in the health facility, and its correlation with maternal mortality. Our research question was: does antenatal care follow up to pregnant women improve the probability of birth in the health facility? Is it correlated with maternal mortality?

\section{METHODS}

\section{Search strategy}

Data were accessed via computer based search from MEDLINE, African Journals Online, HINARI and Google Scholar databases. Additional literature were also searched from websites of major publishers (Elsevier ScienceScience Direct, Nature Publishing Group, Oxford University Press, PsycARTICLES, Science, and Wiley-Blackwell) via HINARI and by searching the reference lists of retrieved articles. The preselected search terms include antenatal care, maternal mortality, maternal mortality ratio, health facility delivery, and skilled person attended delivery.

\section{Inclusion criteria and study selection}

The literature search was done by both authors (YB and $\mathrm{AB}$ ) independently. The inclusion criteria for this this systematic review were: (1) studies that assessed the association of antenatal care with maternal mortality and place of delivery, (2) studies that were written in English and (3) studies published between 2000 and 2013. In this review, national survey data and World Health Organization (WHO) 2013 report in tabular form were included $(8,9)$. Additionally, seventeen small scale studies that report the number of women who had antenatal care, and of these, the number of women who delivered in health facility were included (10-26). The detail description how studies selected and data extracted presented in the preceding article (34).

\section{Data synthesis and analysis}

A bar graph was developed to compare the proportion of antenatal care and health facility delivery by the same individuals who participated in the primary small scale studies. Using data from 
the small scale studies, a meta-analysis of MantelHaenszel odds ratios was conducted. This metaanalysis was done using Review Manager (RevMan) Version 5.1 software. The relation of antenatal care with health facility delivery was determined by performing a regression analysis with Pearson bivariate correlation coefficient using the demographic and health survey (DHS) data of the included African countries. Similarly, a regression analysis of the proportion of antenatal care and health facility delivery with the maternal mortality ratio was done. In this study, health facility delivery means a pregnant woman gave birth in any type of health facility (hospital, health center, private or charity based clinic or hospital).

\section{RESULTS}

\section{Description of studies}

The detail description of the included studies including the methodological quality is found in the preceding article (34).

\section{Findings of the review}

For Figures 1 and 2, WHO and MEASURE DHS databases $(8,9)$ were used as a data sources to compare the national proportion of antenatal care and health facility delivery for those African countries where these two parameters were included in the databases. Figure 1 shows the proportion of pregnant women attending antenatal care at least 4 visits in twenty five Sub Saharan African (SSA) countries in the year 2005-2012. Twelve of the twenty-five included SSA countries were able to achieve $50 \%$ and more coverage of pregnant women with at least 4 antenatal care visits. The minimum antenatal care visits recommended by WHO (4 visits) (28) was possible only for less than about one-third of the pregnant women in some SSA countries like Niger (15\%), Ethiopia (19\%), Chad (23\%), Burundi (33\%) and Mali and Rwanda (35\% each). 


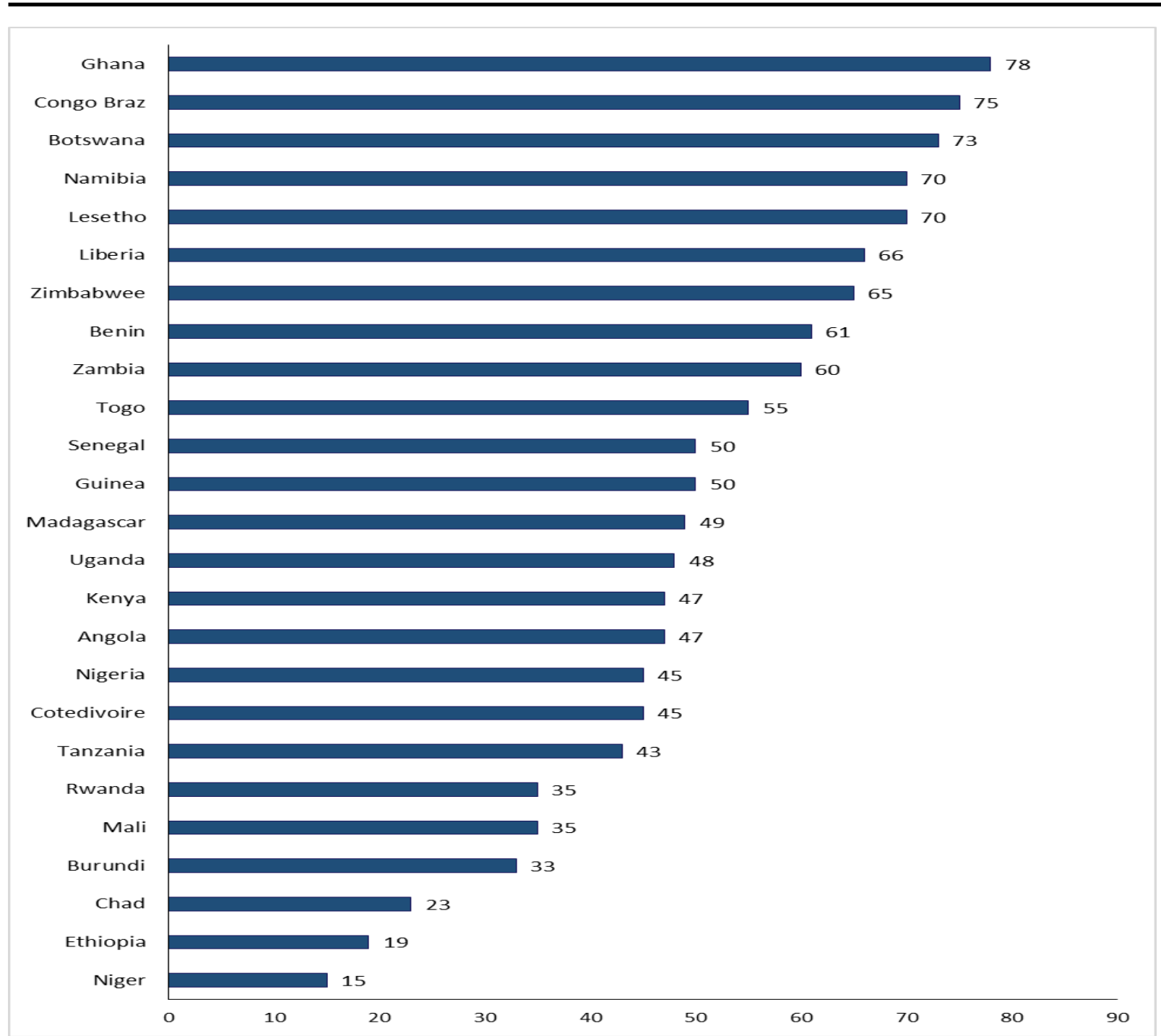

Figure 1: At least 4 visits antenatal care coverage in percent in twenty five Sub Sahara African countries as estimated by World Health organization for 2005-2012

Figure 2 shows the regression analysis of the proportion of pregnant women who received at least four antenatal cares and those who delivered in the health facility. Both the regression line and Pearson bivariate correlation coefficient demonstrated a positive association of antenatal care with health facility delivery $(\mathrm{r}=0.75 ; \mathrm{P}<$ 0.0001). In simple terms, women who attended antenatal care were highly likely to deliver in a health facility. 


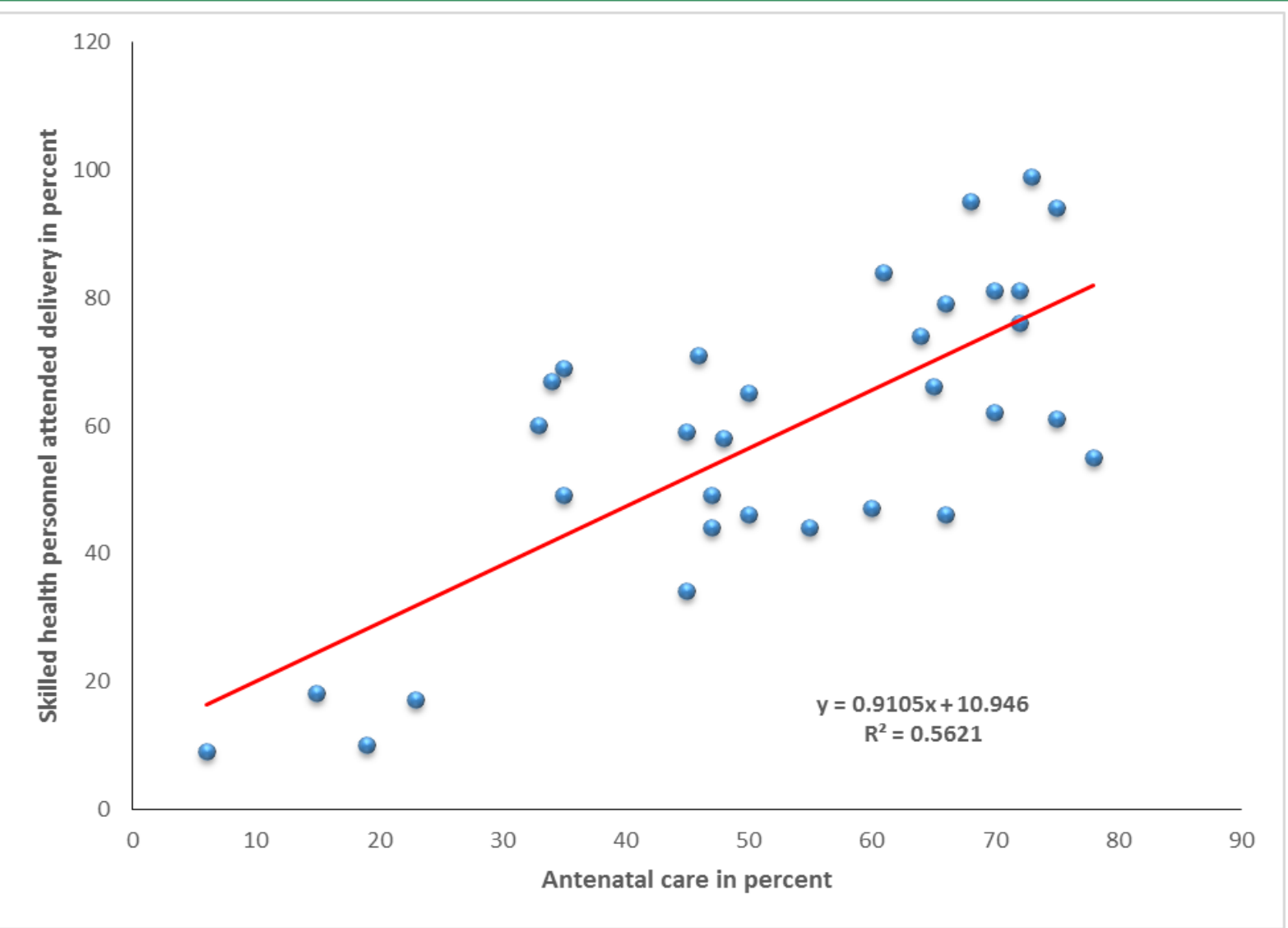

Figure 2: Correlation between proportions of antenatal care (at least 4 visits) and health facility delivery. Pearson bivariate correlation coefficient $(r)=0.75 ; P<0.0001$

However, as shown in Figure 3, all women who had at least one or more antenatal care visits were not coming to a health facility for delivery. Among included countries, although several countries achieved above antenatal care coverage of $90 \%$, the proportion of deliveries in the health facility were below $50 \%$ in Ethiopia, Kenya, Liberia, Madagascar, Nigeria, Sierra Leone, and Tanzania. The discrepancy between the proportions of deliveries in the health facility and at least four antenatal cares were remarkably high particularly in Burundi, Ethiopia, Kenya, Ghana, Liberia, Madagascar, Serra Leone, Tanzania and Uganda. A nearly parallel increase in both antenatal care and health facility was observed in South Africa, Namibia, Zambia and Benin. Of interest, those countries with lower ANC had also lower birth in the health facility (example: Ethiopia and Niger). 


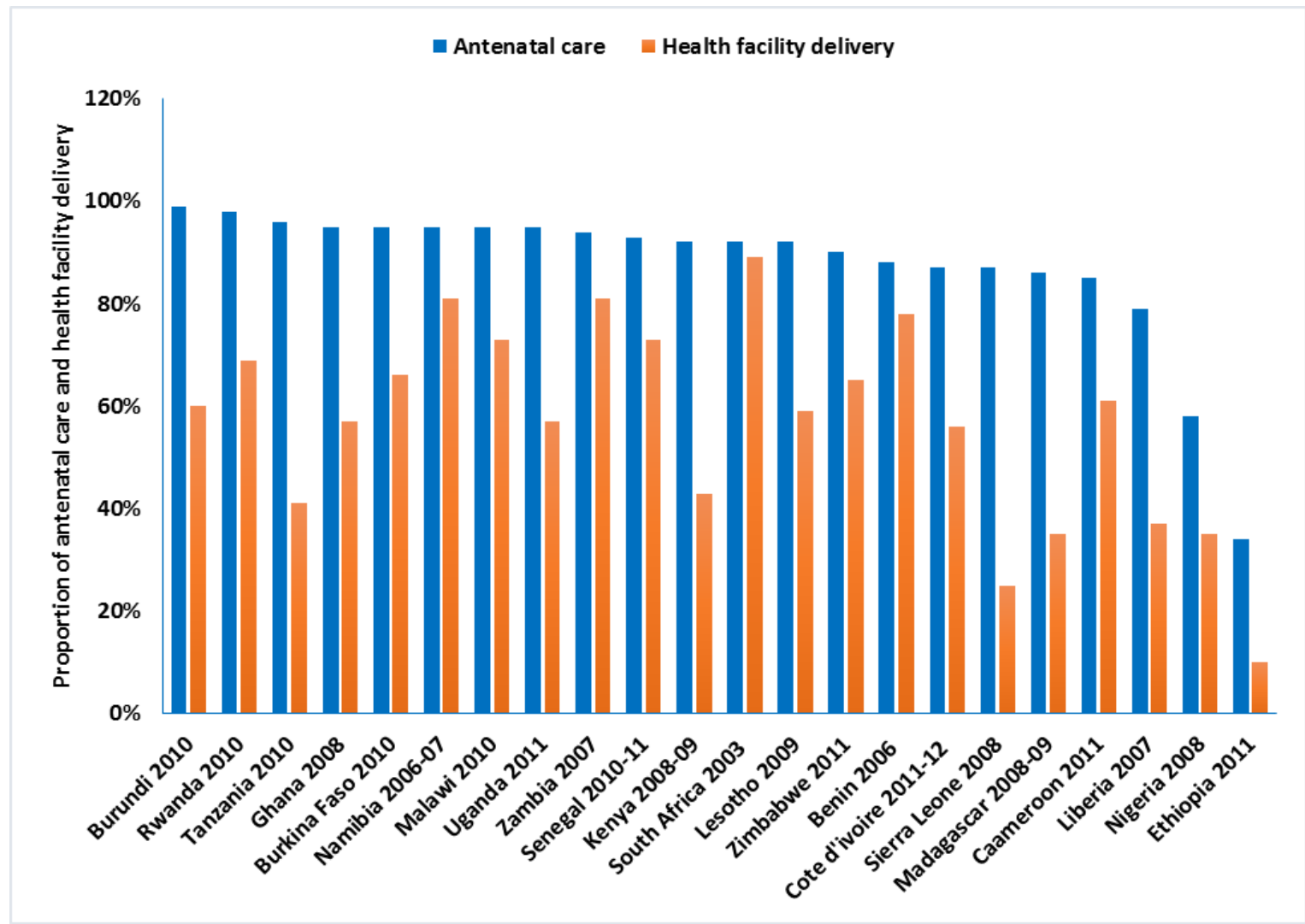

Figure 3: The proportion of antenatal care (at least one visit) and health facility delivery of twenty two Sub Saharan African countries as estimated from their recent national survey data

In Figures 4 and 5, small scale studies on antenatal care and health facility delivery conducted between 2003 and 2013 were included. Figure 4 shows the proportion of at least four antenatal cares and health facility delivery with the same individuals who participated in the primary studies (10-26). In general, the small scale studies also showed the presence of a big gap between the proportion of women receiving antenatal care and those giving birth in health facility. Out of seventeen included studies, the proportion of antenatal care was $50 \%$ and above in thirteen studies $(11,12,14,16,17,19-26)$. With the exception of Wagle RR et al study (32), however, the proportion of health facility delivery in all studies was reported to be in the range of $4 \%$ $45 \%$. Typically, studies on Ethiopia (10-15, 17-19, $21,25,35)$, the proportion of the health facility delivery was extremely lower than the proportion of antenatal care (4\% - $18 \%$ vs $27 \%-82 \%)$. 


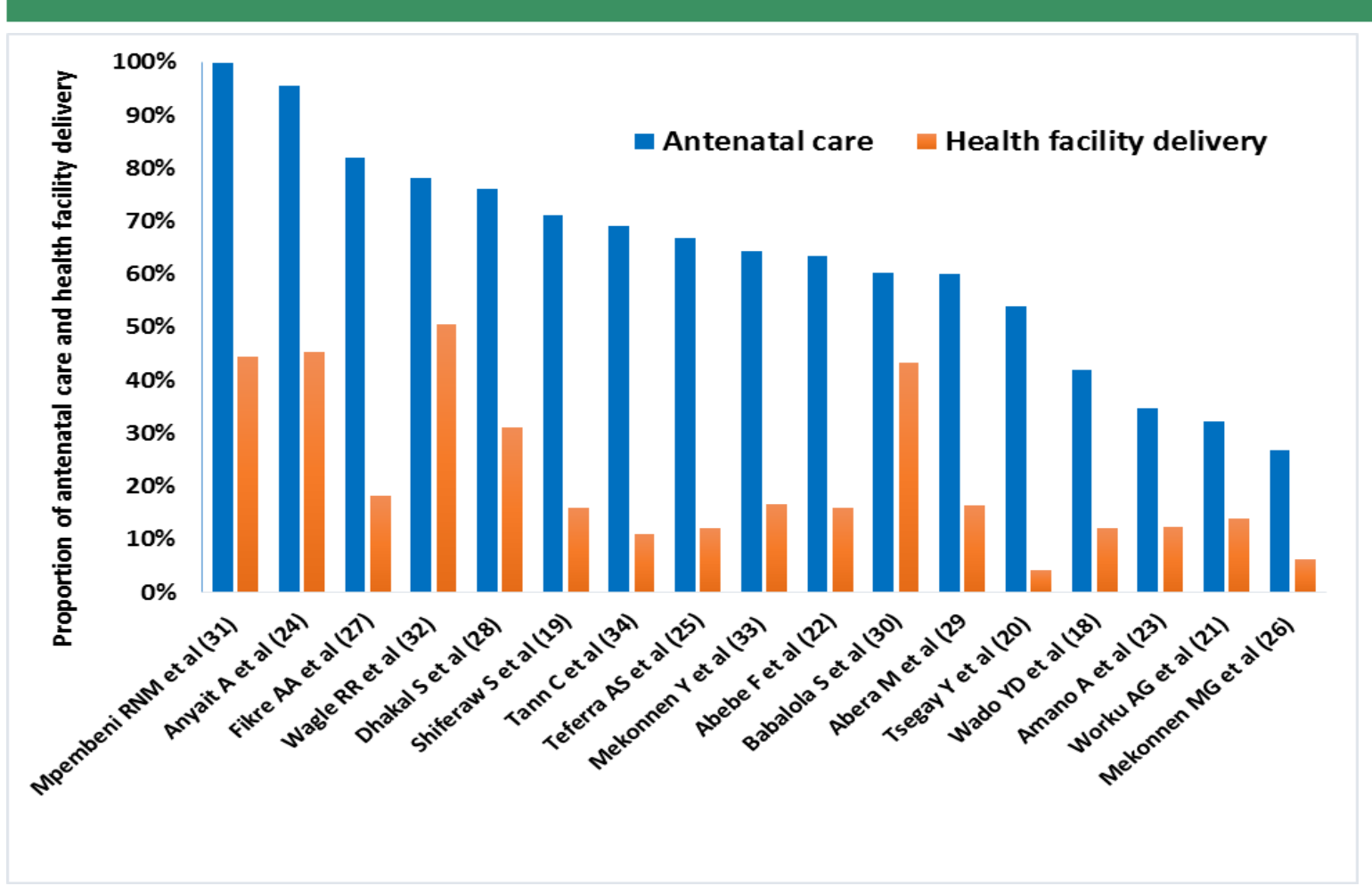

Figure 4: The proportion of antenatal care and health facility delivery (18-34); X-axis: authors' name

A meta-analysis including twelve studies (12-21, 24, 35), however, demonstrated that woman attending antenatal care had more than 7 times increased chance of delivering in a health facility $(\mathrm{OR}=7.1 ; 95 \% \mathrm{CI}, 4.21$ - 12.00) (Figure 5). With the exception of Fikre AA et al study (19), the odds of health facility delivery among women who had antenatal care was 3- to 29 fold higher than those women with no antenatal care. The sensitivity analysis showed the stability of the overall OR; with the exclusion of any one of the studies, there was no change in the association of having antenatal care with increased possibility of health facility based delivery. However, the heterogeneity testing showed significant variability among included studies $\left(\mathrm{I}^{2}=89 \%\right)$; even with the exclusion of any of the studies, the heterogeneity remained high.

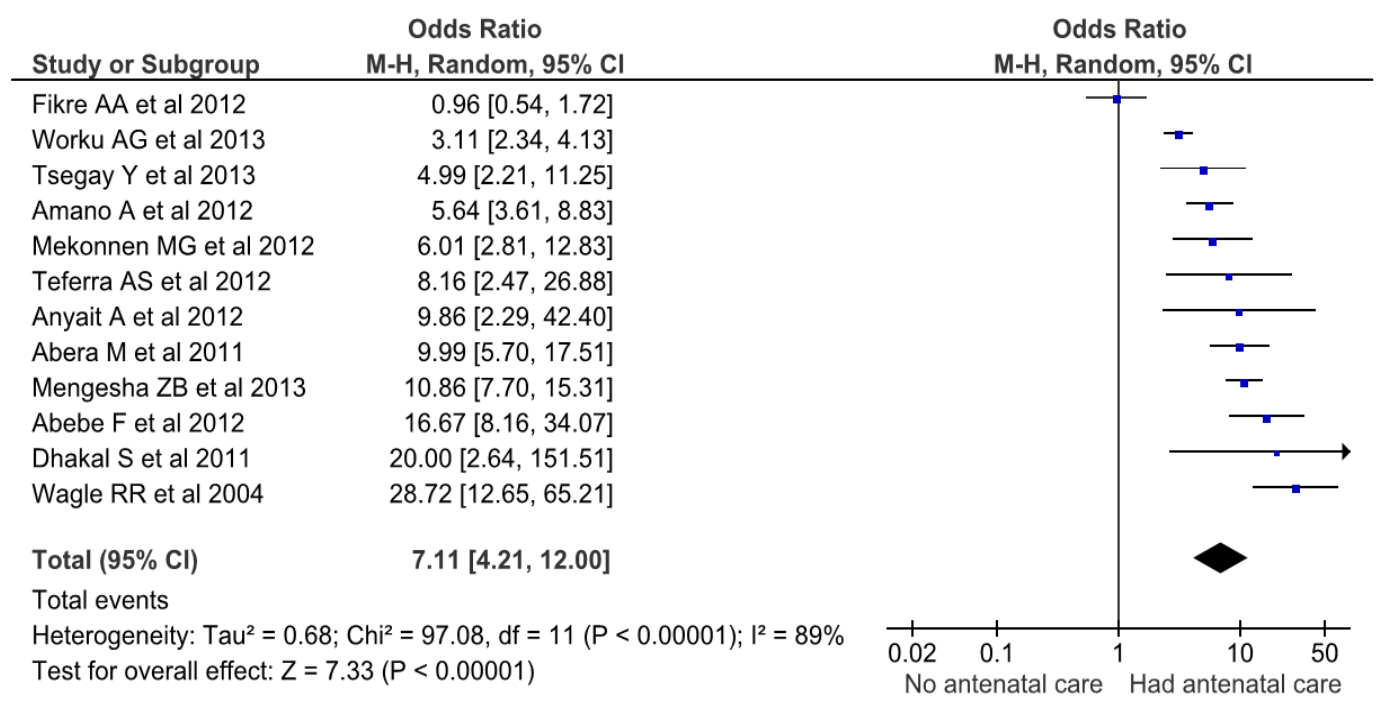

Figure 5: Odds ratio of women's health facility delivery by antenatal care (19-28, 31, 34) 
On the other hand, the positive correlation between antenatal care and health facility delivery observed in Figure 2 was also reflected in the regression analysis with maternal mortality (Figure 6). The regression lines in both antenatal care and health facility delivery were down-going. Health facility based delivery might be more predictive of maternal mortality than antenatal care as the correlation coefficients $(\mathrm{r}=-0.5, \mathrm{P}<$ 0.0001 for antenatal care; $r=-0.7, \mathrm{P}<0.0001$ for health facility delivery) and the regression lines indicated. In short, with an increasing proportion of antenatal care and health facility delivery, there was a progressive drop in maternal mortality ratio per 100, 000 live births.

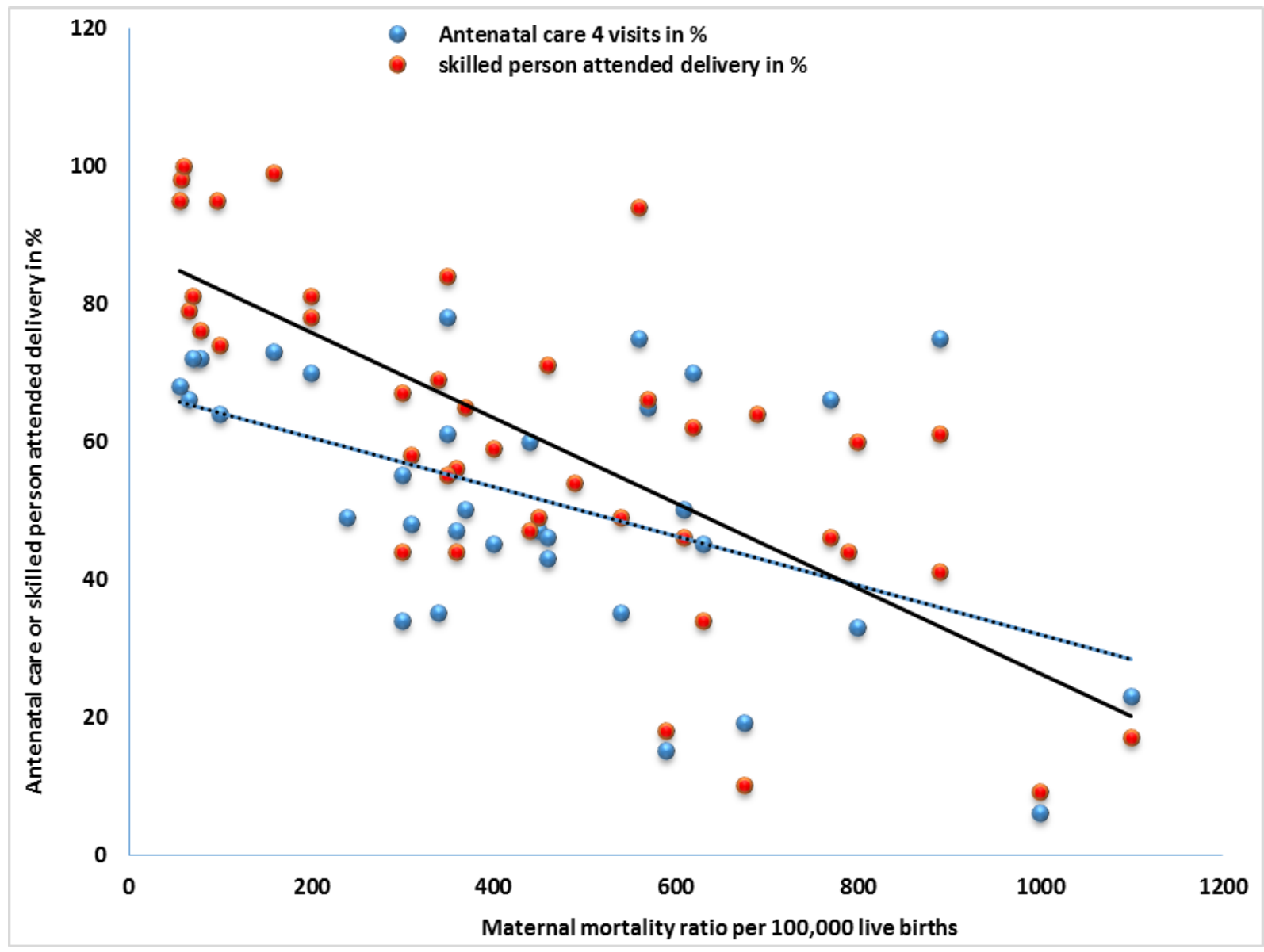

Figure 6: Correlation of antenatal care and health facility delivery with maternal mortality ratio. Pearson bivariate correlation coefficient $(r=-0.5, P<0.0001$ for antenatal care; $r=-0.7, P<0.0001$ for health facility delivery)

\section{DISCUSSION}

This systematic review demonstrated that antenatal care is a very important intervention to increase proportion of birth in the health facility. However, it was also found that the chance of giving birth outside of the health facility was high even among those women who had antenatal care. These two statements may seem contradictory. What it means is that pregnant women who had antenatal care were more likely to deliver in health facilities than those who were not attending antenatal care. However, specific to those pregnant women who had antenatal care, the analysis showed a very significant gap between the proportion of antenatal care and health facility delivery by the same individuals.

Similar observations were reported in several other studies not included in this meta-analysis. There were high facility utilizations for antenatal 
care but most women who accessed antenatal care did not deliver in a health facility $(32,33,26,36$, 37). Otherwise, the strong association of antenatal care with health facility delivery observed in this meta-analysis is consistent with previous reports $(29,37,38)$. The 7 fold increase in health facility delivery among pregnant women attending antenatal care in this analysis was probably because they were already aware of its advantage or they might be well familiar with the health facility environment and the health care providers where they have been attending (38).

Furthermore, the reason for increased health facility delivery among women attending antenatal care may vary among individuals. In general, it is thought that antenatal care gives an opportunity for the pregnant women and her family to be aware of the danger symptoms and potential obstetric complication to come (39). It also creates an informal forum to discuss and share information among pregnant women attending antenatal care in the same facility may give an opportunity to hear stories about pregnant women who were identified as being at higher risk but ended up with uneventful deliveries in health facilities (40). Several other quantitative research findings have also identified the quality of antenatal care as a determinant factor for the increased utilization of health facilities as a place for delivery $(26,37,41)$. Therefore, though the gap between antenatal care attendance and health facility delivery proportion was wide, relatively more pregnant women were coming to health facilities when they had antenatal care. Nevertheless, the reasons for failure to show up for delivery in a health facility despite receiving antenatal care are still areas for further investigations.

However, as other studies demonstrated (34, 42), there are other factors like area of residence, educational level of the couples, wealth status and parity which showed statistically significant association with choosing birth place. Analysis from Kenyan DHS has noted that women from the richest households gave birth more in the health institutions than their counterparts from the poorest households (43).

On the other hand, having antenatal care and health facility delivery seems to have additive effect on maternal mortality reduction. As discussed above, lack of antenatal care was associated with failure to give birth in health facility. Lack of antenatal care and failure to give birth in health facility are likely to delay early detection of pregnancy related complications during pregnancy and delivery, which in turn are likely to increase the risk of maternal mortality. The implication is that the generally low antenatal care utilization in SSA might have contributed to the high maternal mortality as previous reports showed $(8,9,44)$. Other studies have also shown about 10-to 17-fold increased maternal mortality among women with no antenatal care $(45,46)$.

Ethiopia was the least achiever in at least 4 visits antenatal care coverage in SSA. To be more objective, the proportion of health facility delivery and antenatal care between 1995 and 2011 were in the range of $5 \%-10 \%$ and $10 \%-19 \%$, respectively (47). Thus, the low proportion of antenatal care compounded by the extremely low skilled person attended delivery might be some of the major reasons for the high maternal mortality persisting during the last decade (873 and 676 per 100,000 live births in 2000 and 2011, respectively) (47, 48).

This systematic review has several limitations. Because of the lack of quantitative data fit for meta-analysis, pooled analysis was not done on those pregnant women who had antenatal care but failed to deliver in health facilities. Furthermore, the quality of antenatal care which was emphasized as one of the determining factors for coming to health facility during labor $(7,32$, $26,37,41$ ) was not meta-analyzed. Since nine of the seventeen studies included in the univariate analysis and nine of the twelve studies in the meta-analysis were from a single country (Ethiopia), the findings may not be generalizable to all developing countries.

In conclusion, this study has shown a big gap between antenatal care and health facility delivery utilization. Among antenatal care attendees, however, the analyses of data from both national and small scale studies demonstrated a positive correlation of antenatal care with health facility delivery. Having antenatal care has a relative advantage to increase the health facility delivery. But, it was not a solution by itself as there was more than half failure of delivering in health facilities among women who had antenatal care. In other words, antenatal care is a necessary intervention but not a sufficient factor in 
predicting the probability of birth in health facility. Therefore, future research should give emphasis to identifying barriers to health facility delivery among pregnant women who received antenatal care.

\section{ACKNOWLEDGEMENT}

We would like to thank PANE and KMG Ethiopia for the modest financial support granted this review. We are also grateful to UNFPA Ethiopia for their generous financial support to cover the publication fee.

\section{REFERENCES}

1. World Health Organization. Mother-Baby package: Implementing safe motherhood in countries. Practical guide. WHO/FHE/MSM/94.11. World Health Organization 1994.

2. Jacues G. History of Childbirth. Boston: Northern University Press 1991; 96-98. Last accessed in November 2013: http://en.wikipedia.org/wiki/Obstetrics

3. Fiscella K. Does prenatal care improve birth outcomes? A critical review. Obstet Gynecol 1995; 85(3):468-79.

4. McDonagh M. Is antenatal care effective in reducing maternal morbidity and mortality? Health Policy Plan 1996; 11(1):1-15.

5. Villar J, Bergsjo P. Scientific basis for the content of routine antenatal care. Power to eliminate or alleviate adverse maternal outcomes. Acta Obstetricia Gnynecologicia Scandinavica 1997; 76: 1-14.

6. World Health Organization, UNICEF: Antenatal care in developing countries. Promises, achievements, and missed opportunities. Geneva, Switzerland: World Health Organization, 2003.

7. Ram F, Singh A. Is antenatal care effective in improving maternal health in rural uttar pradesh? Evidence from a district level household survey. J Biosoc Sci 2006;38(4): 433-48.

8. Publication search by country (DHS): http://www.measuredhs.com/pubs/

9. World health organization. World Health Statistics 2013. Last accessed in November 2013: www.who.int/.
10. Wado YD, Afework MF, Hindin MJ. Unintended pregnancies and the use of maternal health services in southwestern Ethio pia. BMC Int_Health Hum Rights 2013; 13:36. doi: 10.1186/1472-698X-13-36.

11. Shiferaw S, Spigt M, Godefrooij M, Melkamu Y, Tekie M. Why do women prefer home births in Ethiopia? BMC Pregnancy Childbirth 2013; 13:5. doi: 10.1186/14712393-13-5.

12. Tsegay Y, Gebrehiwot T, Goicolea I, Edin K, Lemma H, Sebastian MS. Determinants of antenatal and delivery care utilization in Tigra y region, Ethiopia: a cross-sectional study. Int $J$ Equity Health 2013;12:30. doi: 10.1186/1475-9276-12-30.

13. Worku AG, Yalew AW, Afework MF. Factors affecting utilization of skilled maternal care in Northwest Ethiopia: a multilevel analysis. BMC Int Health Hum Rights 2013; 13:20. doi: 10.1186/1472-698X-13-20.

14. Abebe F, Berhane Y, Girma B. Factors associated with home delivery in Bahirdar, Ethiopia: a case control study. BMC Res Notes 2012; 5:653. doi: 10.1186/1756-0500-5-653.

15. Amano A, Gebeyehu A, Birhanu Z. Institutional delivery service utilization in Munisa Woreda, South East Ethiopia: A community based cross-sectional study. BMC Pregnancy Childbirth 2012; 12:105. doi: 10.1186/1471-2393-12-105.

16. Anyait A, Mukanga D, Oundo GB, Nuwaha F. Predictors for health facility delivery in Busia district of Uganda: a cross sectional study. BMC Pregnancy Childbirth 2012; 12:132. doi: 10.1186/1471-2393-12-132.

17. Teferra AS, Alemu FM, Woldeyohannes SM. Institutional delivery service utilization and associated factors among mothers who gave birth in the last 12 months in Sekela District, North West of Ethiopia: A community - based cross sectional study. BMC Pregnancy and $\begin{array}{lll}\text { Childbirth } & \text { 2012; } & \end{array}$ http://www.biomedcentral.com/

18. Mekonnen MG, Yalew KN, Umer JY, Melese M. Determinants of delivery practices among Afar pastoralists of Ethiopia. Pan Afr Med J 2012; 13 Suppl 1:17.

19. Fikre AA, Demissie M. Prevalence of institutional delivery and associated factors 
in Dodota Woreda (district), Oromia regional state, Ethiopia. Reprod Health 2012; 9:33. doi: 10.1186/1742-4755-9-33.

20. Dhakal S, van Teijlingen E, Raja EA, Dhakal KB. Skilled care at birth among rural women in Nepal: practice and challenges. $J$ Health Popul Nutr 2011; 29(4):371-8.

21. Abera M, G/Mariam, Belachew T. Predictors of safe delivery service utilization in Arsi Zone, South-East Ethiopia. Ethiop J Health Sci 2011; special issue. 101-113.

22. Babalola S, Fatusi A. Determinants of use of maternal health services in Nigeria-looking beyond individual and household fact ors. BMC Pregnancy Childbirth 2009; 9:43. doi: 10.1186/1471-2393-9-43.

23. Mpembeni RN, Killewo JZ, Leshabari MT, et al. Use pattern of maternal health services and determinants of skilled care during delivery in Southern Tanzania: implications for achievement of MDG-5 targets.

$B M C$ Pregnancy Childbirth 2007; 7:29. http://www.biomedcentral.com

24. Wagle RR, Sabroe S, Nielsen BB. Socioeconomic and physical distance to the maternity hospital as predictors for place of de livery: an observation study from Nepal. $B M C$ Pregnancy $\quad$ Childbirth 2004; 4(1):8. http://www.biomedcentral.com

25. Mekonnen Y, Mekonnen A. Factors influencing the use of maternal health services in Ethiopia. J Health_Popul Nutr 2003; 21(4):374-82.

26. Tann CJ, Kizza M, Morison L, et al. Use of antenatal services and delivery care in Entebbe, Uganda: a community survey. $B M C$ Pregnancy Childbirth 2007; 7:23. http://www.biomedcentral.com

27. JHPIEGO/Maternal and neonatal health: Prevention and control of malaria during pregnancy. Reference Manual for health care providers, 2003.

28. Villar J, Ba'aqeel H, Piaggio G, et al. WHO antenatal care randomised trial for the evaluation of a new model of routine antenatal care. Lancet 2001; 357(9268):155164.

29. Lincetto O, Mothebesoane-Anoh S, Gomez P, Stephen Munjanja. Antenatal care in Opportunities for Africa's Newborns. World Health Organization publication 2006. Last accessed in November 2013: http://www.who.int/

30. Hailu M, Gebremariam A, Alemseged F, Deribe K. Birth Preparedness and Complication Readiness among Pregnant Women in Southern Ethiopia. PLoS ONE 2011; 6(6): e21432. doi:10.1371/journal.pone.0021432

31. United States Agency for International Development (USAID). Focused antenatal care: Providing integrated, individualized care during pregnancy. USAID 2007. Last accessed in November 2013: http://www.accesstohealth.org/toolres/pdfs/

32. Rockers PC, Wilson ML, Mbaruku G, Kruk ME. Source of antenatal care influences facility delivery in rural Tanzania: a population-based study. Matern Child Health J 2009; 13(6):879-85.

33. Magoma M, Requejo J, Campbell OMR, Cousens S, Filippi V. High ANC coverage and low skilled attendance in a rural Tanzanian district: a case for implementing a birth plan intervention. BMC Pregnancy and Childbirth 2010; 10:13. http://www.biomedcentral.com/

34. Berhan Y, Berhan A. A meta-analysis of socio-demographic factors predicting birth in the health facility. Ethiop J Health Sci 2014. Special issue 1.

35. Mengesha ZB, Biks GA, Ayele TA, Tessema GA, Koye DN. Determinants of skilled attendance for delivery in Northwest Ethiopia: a community based nested case control study. BMC Public Health 2013; 13: 130. doi: 10.1186/1471-2458-13-130.

36. Oguntunde O, Aina O, Ibrahim MS, Umar HS, Passano P. Antenatal Care and Skilled Birth Attendance in Three Communities in Kaduna State, Nigeria Afr J Reprod Health 2010; 14(3): 89-96.

37. Pervin J, Moran A, Rahman M, et al. Association of antenatal care with facility delivery and perinatal survival - a populationbased study in Bangladesh. BMC Pregnancy Childbirth 2012; 12: 111. doi: 10.1186/14712393-12-111.

38. WHO, UNICEF. Antenatal care in developing countries: promises, achievements and missed opportunities: an analysis of trends, levels and differentials, 1990-2001. Last accessed in 
November

2013:

www.childinfo.org/files/antenatal_care.pdf

39. Palaniappan B. Role of antenatal care in Safe Motherhood. J Indi Med Asso 1995: 93:52-54

40. Lilford RJ, Chard T. Problems and pitfalls of risk assessment in antenatal care. BJOG 1983; 90:507-510.

41. Bloom SS, Lippeveld T, Wypij D. Does antenatal care make a difference to safe delivery? A study in urban Uttar Pradesh, India. Health Policy Plan 1999; 14(1):38-48.

42. Yesuf EA, Kerie MW, Calderon-Margalit R. Birth in a health facility--inequalities among the Ethiopian women: results from repeated national surveys. PLoS One 2014; 9(4):e95439. doi: 10.1371/journal.pone.0095439.

43. Kitui J, Lewis S, Davey G. Factors influencing place of delivery for women in Kenya: an analysis of the Kenya demographic and health survey, 2008/2009. BMC Pregnancy and Childbirth 2013; 13: 40. Retrieved from: 2393/13/40.

44. Hogan MC, Foreman KJ, Naghavi M, et al. Maternal mortality for 181 countries, 1980 2008: a systematic analysis of progress towards Millennium Development Goal 5. The Institute of Health Metrics and Evaluation (IHME) at the University of Washington in Seattle, USA. Lancet 2010; 375: 1609-23

45. Garenne M, Mbaye K, Bah MD, Correa P. Risk factors for maternal mortality: a casecontrol study in Dakar hospitals (Senegal). Afr J Reprod Health 1997; 1(1):14-24.

46. Igberase GO, Ebeigbe PN. Maternal mortality in a rural referral hospital in the Niger Delta, Nigeria. Obstet Gynaecol 2007; 27(3):275-8.

47. Central Statistical Agency [Ethiopia] and ICF International. 2012. Ethiopia Demographic and Health Survey 2011. Addis Ababa, Ethiopia and Calverton, Maryland, USA: Central Statistical Agency and ICF International.

48. Federal Democratic Republic of Ethiopia. Ministry of Health and Health Related Indicators 2010/2011). Policy planning directorate. www.moh.gov.et 